\title{
Development of Social Intelligence in Preschool Children by Art Therapy: Case Study of Oyna Educational Centre
}

\author{
Akhmetzhan S. Seitenov \\ Ahseyt LLC, Pavlodar, Republic of Kazakhstan \\ https://orcid.org/0000-0002-1767-3274 \\ Rakhila Zh. Aubakirova \\ Pavlodar State University, Pavlodar, Republic of Kazakhstan \\ https://orcid.org/0000-0002-7984-2387 \\ Alyona A. Kostyunina and Ekaterina V. Mishchenko \\ Gorno-Altai State University, Gorno-Altaisk, Russian Federation \\ https:// orcid.org/0000-0001-9055-6472 \\ https://orcid.org/0000-0003-2820-9167 \\ Natalya B. Shevchenko \\ Altai State Humanitarian and Pedagogical University, Biysk, Russian Federation \\ https:// orcid.org/0000-0001-5763-5021
}

\begin{abstract}
The objective of this research paper is to elaborate methods for the development of social intelligence of preschool children by means of art therapy. Using the Tromsø Social Intelligence Scale cognitive, behavioural and affective criteria are refined with the corresponding indicators of the levels of development of social intelligence in preschool children. The methodology was implemented at the following stages: the preparatory one was characterized by an emotional mood, rallying the children's team, and diagnosing interpersonal relationships, the main one is both summative and formative, which provides for training, and the final one is summing up with the help of a diary of pedagogical observations. The description of art-therapeutic methods, in particular, fairy-tale therapy, game therapy, drama therapy and isotherapy used in working with children are presented. The paper substantiates the need to test the effectiveness of the developed methodology in the process of empirical research and the adaptation of the Tromsø Scale to diagnose the levels of development of social intelligence in preschool children. In addition, the preparation of teachers for work, sharing and assimilation of the acquired pedagogical experience in the teaching process of preschool educational institutions was covered.
\end{abstract}

Keywords: social intelligence; development; preschool child; art therapy 


\section{Introduction}

Preschool age is the basis for the formation of the child's personality. UNESCO (2018) determines early childhood (from birth to the age of eight) as the peak period of brain development. At this stage, children are significantly affected by the environment and people. In this regard, the education and upbringing of preschool children should be directed not only at preparing for primary school, but also at the holistic development of the child's social, emotional, cognitive and physical needs in order to build a solid foundation for life-long learning, as well as personal, social and physical well-being (UNESCO, 2018). The World Health Organization (WHO) notes that children are the future, and ensuring their physical, socio-emotional, verbal and cognitive development should be a priority for all societies (WHO, 2019). The Incheon Declaration (UNESCO, 2016) notes, that quality education stimulates creative spirit and knowledge, guarantees the acquisition of basic literacy and numeracy skills, as well as the skills, of analysing, problem solving and other high-level cognitive, interpersonal, and social skills. Therefore, the development of social intelligence of a child of preschool age and the development of appropriate methodological support for the implementation of this process is an urgent problem.

Analysis of the scientific literature demonstrates the diversity of definitions of the concept of "social intelligence". Wedeck (1947) understood it as the ability to properly assess the feelings, moods and motivations of people. Robinson (1947) believed that the basis of a child's social intelligence contained knowledge of himself and relationships with other children, the ability to make decisions on interaction with others and act according to these decisions. Bailey (2002) has a similar opinion, noting that social intelligence includes complex social skills that reflect the ability to understand other people's hidden mental states and act based on these findings. Buzan (2002) distinguished eight groups of skills in the structure of social intelligence, namely: 1) understanding and cognizing people through verbal and non-verbal signals; 2) active listening; 3) sociability; 4) influencing others; 5) social activity; 6) negotiating and solving social problems; 7) persuasion of others; 8) orientation and behaviour in different social environments.

Doğan and Çetin (2009), summarizing the essence of social intelligence based on the analysis of scientific works of other authors concluded that there are four related issues that need to be resolved. First, this is the correct definition of this concept. Silvera, Martinussen and Dahl (2001) found out that some psychologists question the existence of this formation and its expediency, since it is difficult to measure it in the process of empirical research. The authors see the solution to this problem in defining social intelligence as a multiaspect formation, which will allow establishing its connection with other psychological formations.

Secondly, it is necessary to identify the components of social intelligence as a complex phenomenon. It is important to note that most authors define social intelligence as a combination of certain components, distinguishing not only cognitive (knowledge) and behavioural (skill) components, as mentioned above, but also motivational (social needs and interests) (Astramovich, Lyons \& 
Hamilton, 2015; Nolan \& Paatsch, 2018; Rodney et al., 1988) and affective (emotions and feelings) (Kaukainen et al., 1999; Kisida, Bowen \& Greene, 2018; Wawra, 2009) components. Thirdly, it is necessary to clarify whether social intelligence is an independent formation and establish its connection with the intelligence itself. Doğan and Çetin (2009), referring to the opinions of predecessor scientists, conclude that social intelligence and academic intelligence are two separate structures that are independent, however, complement each other.

Fourthly, as the researchers note, the procedure for measuring social intelligence and selecting appropriate diagnostic tools is quite complicated. Despite the existence of many methods in the psychological and pedagogical literature, most of them are focused on the measurement of a particular trait, for example, the cognitive or behavioural component of social intelligence. Therefore, it is advisable to refer to the Tromsø Social Intelligence Scale, developed by Norwegian scholars (Silvera et al., 2001), which, in our opinion, most meaningfully reflects the components of social intelligence (cognitive, affective and behavioural). It is worth noting that this methodology was tested by its authors to determine the level of social intelligence of teachers and students of higher educational institutions, as well as by Turkish scholars (Doğan \& Çetin, 2009), who similarly tested the validity and reliability of this methodology in the process of working with university students. For the first time, Russian scholars tested the Tromsø Social Intelligence Scale for schoolchildren; its high reliability for various age and gender groups was revealed and subscale test norms for students aged 7-16 years were developed (Enygin, Fominykh, Bubenchikova, Arregi-Orue \& Aubakirova, 2018; Fominykh, Barsova, Zarudnaya \& Kolomiytseva, 2016; Nasledov \& Semenov, 2015; Zarudnaya et al., 2018). However, the potential of the proposed methodology for measuring the level of social intelligence in preschool children is insufficiently studied.

We believe that there is a fifth issue related to social intelligence, which is poorly studied in scientific works and requires careful analysis and systematic study, namely the development of methodological support for the development of social intelligence of preschool children, which is the objective of this study.

\section{Materials and Methods}

The experiment involved 12 children of the experimental group. The following research methods were used in the study: analysis and generalization of scientific literature in order to generalize and study the research problem, pedagogical observation with the use of a diary for pedagogical observation of children, recording the qualitative changes that occur in the process of introducing methods of developing social intelligence in preschool children by means of art therapy, SWOT-analysis is a method of strategic planning, in order to identify strengths, weaknesses, opportunities, threats) and pedagogical modeling which is the introduction of art-therapeutic methods and techniques on the basis of Oyna Training Centre in Pavlodar, Republic of Kazakhstan. The Tromsø Social Intelligence Scale was used to refine the criteria and indicators of the levels of social intelligence in preschool children. 


\subsection{Pedagogical Modelling}

The methodology of the development of social intelligence in preschool children by means of art therapy was developed in the study, the stages of its implementation were identified; appropriate art-therapeutic methods and techniques were selected; this methodology has been introduced on the basis of Oyna Educational Centre in Pavlodar, the Republic of Kazakhstan. In the process of developing the methodology, scientific works of the scholars (Van Oers \& Duijkers, 2013; Taber, 2013; Katzmann, Goertz-Dorten, Hautmann \& Doepfner, 2018; Mora, van Sebille \& Neill, 2018;) were used, which justified the creation of methodologies for teaching and developing children on the basis of art therapy, in particular, game therapy, since the leading activity of children of preschool age is gaming. The experience of scholars (Bachar, 2008; Cutter-Mackenzie \& Edwards, 2013; Robson \& Rowe, 2012; Müller, Naples, Cannon, Haffner \& Mullins, 2018) was taken into account, who proved the effectiveness of using works of art and attracting children to create them for the harmonious development of preschool children.

\subsection{The Tromsø Social Intelligence Scale}

The method of Norwegian researchers (Silvera et al., 2001) is used to refine the criteria and indicators of the levels of development of social intelligence in preschool children. The criteria are determined on the basis of three subscales: processing social information, social skills and social awareness. Cognitive indicators indicate the subject's ability to understand the desires, aspirations, intentions and feelings of others through verbal or non-verbal signals, predict other people's behaviour, their feelings and reactions to the actions of the subject. Behavioural indicators assess the ability to easily adapt to new situations of communication, to initiate and maintain interaction with others, choosing the right words and topics for communication and affective indicators measure the susceptibility to events and reactions to others in interpersonal interactions.

\subsection{Diary of Pedagogical Observations}

In the process of pedagogical research, it is appropriate to use both quantitative, and qualitative research methods. Such methods, according to Nind and Lewthwaite (2018), allow obtaining more meaningful and in-depth information, identifying factors affecting the object of study, the causes and consequences of its condition. We use a diary for pedagogical observation of the children of the experimental group (12 people) and to record the qualitative changes occurring in the process of implementing the methodology of the development of social intelligence in preschool children by means of art therapy. The basis for building a diary is a SWOT analysis (Strengths, Weaknesses, Opportunities, Threats) to record the strengths and weaknesses of a child's personality, reflecting the degree of formation of social intelligence according to cognitive, behavioural and affective criteria, and "Opportunities" are formulated as guidelines for further work in order to intensify strengths and eliminate weaknesses. Nind and Lewthwaite (2018) suggest using the diary not only as a method of pedagogical self-observation, but also as a way of exchanging opinions with colleagues. We consider it expedient to organize the cooperation of a teacher with the child's parents with the help of a diary to increase the efficiency of the methodology. 


\section{Findings}

Oyna Educational Centre (Pavlodar, Republic of Kazakhstan) pays special attention to the education, upbringing and development of preschool children based on the synthesis of advanced pedagogical experience from various countries of the world (Finland, Hungary, Singapore, Japan). At the same time, it is important to preserve the national Kazakh traditions of teaching and upbringing, which is achieved through the use of an ethnological material. In the process of work with children, the methods of art therapy, fairy-tale therapy, drama therapy, game therapy and isotherapy are widely used, and, in addition, their educational potential for the development of social intelligence is determined. Isotherapy is the therapy by fine arts, first of all drawing, which is currently used for psychological correction of clients with neurotic, psychosomatic disorders, children and adolescents with difficulties in learning and social adaptation, in the family conflicts. The methodology of development of social intelligence in preschool children by means of art therapy is implemented in three stages as detailed below.

\subsection{Preparatory}

The purpose of this stage is the emotional mood of children to effectively interact with each other, ensuring group cohesion and diagnosing interpersonal relationships in the children's team. Pedagogically valuable is the use of icebreaking games: "Acquaintance", "Find the one who ...", with the help of which children are directed towards initiating communication with each other, displaying positive emotions, spontaneous expression of feelings. It is also advisable at this stage to identify the overall level of relationships in the children's group and rank the participants from the category of "rejected" to the category of "stars", that is, the children who enjoy popularity and sympathy in the group. For this purpose, the methods of sociometry and the method of projective drawing as a type of isotherapy are used. Each child is invited to draw himself in the centre of the sheet as the sun or the moon, and to "place" the other members of the group in the form of stars around. Thus, the child draws those to whom he feels sympathy and trust closer to himself. The information contained in the drawings of children is processed by the educator and transformed into a sociogram, which is also a drawing in which members of the group are drawn as geometric figures. These figures are connected by arrows, which reflect the nature of the relationship in the children's group. This allows forming microgroups of children for the joint solution of a certain educational task in the future work.

\subsection{Main (summative and formative)}

Its goal is to develop the social intelligence in preschool children in terms of cognitive, behavioural and affective criteria through a special training that combines the signs of role-playing, communicative and sensitivity trainings. Using a combination of fairy-tale therapy and game therapy, the child's social intelligence is developed according to cognitive criteria, and the task of the educator is to direct the children involved towards: predicting other people's behaviour and understanding of feelings, desires, intentions of other people using, among other things, words, gestures, facial expressions and other means. 
Lessons with children are built on the basis of the plot of a particular fairy tale or a series of fairy tales. It is known that a preschool child will never remain indifferent if what he does is connected with the world of fairy tales, fantasies, games and things that are close to him (hobbies, friends). Practical experience with children indicates the appropriateness of using Kazakh folk tales about animals, for example, Tiger and Mouse, Dog Assessment, Cautious Bunny, Small Bunny, and others. It requires an analysis of fairy tales which are based on the interaction of subjects with children. We share the point of view of Sidorchuk and Khomenko (1998), who believe that the traditional approach to the analysis of literary works with preschool children through a detailed study of the causal relationships of the interaction of heroes and the identification of their characteristics has several disadvantages: due to psycho-physiological features children quickly lose interest in analysing the content of a work, almost do not see identical models in works, cannot draw analogies between different situations.

Therefore, in our work we use the method proposed by the authors for analysing a literary work with the help of the "Yes-No" situational game:

1. Inaccurately compiled text code of any literary work is deliberately delivered. For example, analysing the fairy tale Dog Assessment, the following statement is formulated: "A kind person, coming up to me, starts shouting, making noise, swearing"

2. The main rule of the game is reported: generalized questions should be asked in such a way that the presenter (teacher or child) can answer "Yes" or "No". Questions concerning the names of the characters or the names of the fairy tale remain unanswered.

3. Questions are structured in accordance with the algorithm for deciphering the details (signs) of the situation. At the same time, we omit such points proposed by the authors as clarifying the level of reality and establishing the genre of the work, since it is already known that this is a fairy tale. Other questions are arranged in the following order: clarification of the signs of the first object, clarification of the signs of the second object, determining the place where the objects interact, determining the time of interaction, determining relationships between the objects and finding out the characteristics of secondary objects.

4. After each clarified step, the text with established features is gradually built. It is necessary to reformulate and clarify the original statement ("A good person, coming up to me, does not touch me and silently passes me by, and a bad person begins to scream, make noise, swear") and continue the work with the adjusted task.

5. The text enriched with clarified characteristics is reproduced by children in the final version.

6. Search for analogies: children give examples of other fairy tales that are based on a similar model.

7. Return to the put-up fairy tale. Children should clarify the content of the work and write a new text "Yes-No".

8. Determination of the version of the fairy tale most accurately compiled (in terms of the plot) fairy tale. 
The next is a combination of such art therapy methods as drama therapy, game therapy and isotherapy, which allows the development of a child's social intelligence according to behavioural and affective criteria. The task of the educator is to develop in participating children susceptibility to the events and reactions of others in interpersonal interaction, as well as the ability to: adapt to new situations of communication and to initiate and support interaction with others, selecting the right words and topics for communication. At this stage, staging of fairy tales, which were analysed, and the role-playing of participating children is appropriate. Dramatization is interesting when the rest of the participants are not informed of the name of the fairy tale and they have to guess it, carefully watching the play of the "actors".

We also use the recommendations of Edwards (2017) on the use of three types of games: open-ended, modelled and purposefully framed. The goal of the openended game is the assimilation of a new concept by children in the process of their own search activity, and the techniques are observation, experiment; the goal of the modelled game is the assimilation of a new concept by children through its demonstration in action by the teacher, and the techniques are demonstration, explanation; the goal of the third type of games is the assimilation by children of a new concept in joint activities with a teacher through the study of various information sources, and the techniques are discussion, open questions, observations, use of resources, transfer of previously acquired knowledge to a new situation.

For example, continuing the study of the topic "Animals", we conduct an openended game with children, combining game therapy and isotherapy. At first, children are divided into search groups, the participants are offered cards with the image of wild animals, and each group selects a research topic related to a certain animal (for example, one of those living in the Republic of Kazakhstan). The purpose of the research is to study the features, behavioural patterns of an animal, associations with it, ideas that arise. We consider the possibility of living observation of the object of research to be pedagogically valuable, therefore we organize a visit with the children to the zoo or museum. The next is to collect data about the object. The children record the obtained information using the writing panel - drawings, symbols, signs, children perform together in search groups. In addition to observations, we encourage children to "interview experts" - other people, relatives, acquaintances. This allows not only supplementing knowledge about the object of research, but also develops the ability of children to initiate communication not only with their peers, but also with older people. As practice shows, the most difficult thing for a child is to summarize the data obtained, so the educator must help him with this, tell him which details are basic and which are secondary. At the end, the participants of each search group define a new concept, characterizing its features, giving examples and the like. Members of other groups are encouraged to ask questions, discuss the submitted report. Such a collective research work contributes both to the acquisition of research experience by children, and teaches teamwork and adaptation to various communication situations. 
At the summative and formative stage, it is important to comply with the requirements of the training, namely:

1) children should be about the same age (5-6 years);

2) during the training, the educator maintains a positive atmosphere, focusing on the successful actions of children, which ensured the effectiveness of interpersonal communication;

3) activity, initiative, spontaneity, sincere expression of feelings is encouraged.

It is necessary to determine the conditions under which the training will be productive, namely:

1) relationship of education, upbringing and development;

2) correspondence of the methods, techniques and forms of training to psychophysiological nature of a child;

3) educational cooperation of children;

4) ensuring the physical and emotional well-being of a child is to create a state of comfort, confidence and success for the children during the entire period of the training.

\subsection{The final stage, aimed at summarizing with the help of a diary of} pedagogical observations

The level of formation of social intelligence in the child is determined according to the indicators based on the modified version of the Tromsø Social Intelligence Scale (Table 1).

Table 1: Level of formation of social intelligence in the child

\begin{tabular}{|l|l|}
\hline Choice & Quality \\
\hline 4 - Strongly Disagree & Quality is stable, manifests itself continuous \\
\hline 3 - Agree & Quality is stable, manifests itself in most cases \\
\hline 2 - Undecided & Quality is unstable, its manifestation is situational \\
\hline 1 - Disagree & Almost no quality \\
\hline 0 - Strongly Disagree & No quality \\
\hline
\end{tabular}

It is important to trace the dynamics of the results before and after the implementation of the methods of development of social intelligence in preschool children. The data obtained as a result of pedagogical observation allow us to carry out a SWOT analysis: to identify the child's strengths and weaknesses as internal factors, and to identify opportunities and threats as external factors. Based on the SWOT analysis, recommendations for parents are formulated, for example:

1. As often as possible, ask Kaisar to tell what he thinks about one or another life situation, discuss the development of the plot in a fairy tale or cartoon. In order to understand cause-effect relationships, ask your son: "Why did the heroes do this? Could they have done differently? What could follow?" In order for Kaisar to understand the mood of another person, sympathize with him and learn to sincerely express his feelings, tell him more often what you feel in a given situation and why. 
2. Amina often seeks support and patterns her behaviour on her brother; this makes it impossible to build her own strategies of social behaviour. Therefore, she needs to be taught to initiate interaction with others, to demonstrate her reactions to their actions, to actively manifest herself in the society. Try to express her unconditional acceptance to the child, not because she does something good or behaves correctly, but because you accept her as she is. Find an opportunity to encourage her independence and initiative.

The need to keep a diary of pedagogical observations in order to develop the social intelligence of a preschool child is supported by the results of a study by McLeod et al. (2018), who discovered that educators and parents are more concerned about the development of the speech of children and their expressiveness than their behaviour in society, readiness for school, independence, and the like. This indicates that both parents and educators, as subjects of pedagogical influence, underestimate the importance of developing the child's social intelligence for his successful self-realization in society.

A sample diary to characterize a preschool child according to these three criteria are provided in Appendix 1.

\section{Conclusion}

In the study, the concept of "social intelligence of a preschool child" is defined as a combination of cognitive, behavioural, and affective components that reflect the essence of social intelligence as a multiaspect formation. It is worth noting that when introducing the methods of developing the social intelligence of preschool children with art therapy means, the educator's preparation for the implementation of the methodology is particularly significant. In this regard, the educator is an important socializer, ensuring that learners acquire social and emotional experience, teaching them to overcome emotional and behavioural problems. Therefore, in our opinion, it is appropriate to conduct psychopedagogical training for educators in order to form their readiness for work with preschool children, aimed at developing their social intelligence by means of art therapy. At the same time, self-diagnosis and self-development by educators of their own social intelligence are important for productive work with children. The practical significance of the results lies in the fact that methods for the development of social intelligence of preschool children by means of art therapy have been developed and implemented. In the future, it will allow specialists to identify the characteristics of the child's mental organization and contribute to its successful socialization and adaptation in general in educational institutions. The outcomes from this study can be used in the preparation and advanced training of specialists majoring in Psychology, in particular in the process of preparing lectures and practical classes on social psychology, personality psychology, pedagogical psychology, special courses and special seminars.

It was revealed that the leading art therapeutic method in the process of implementing the developed methodology is game therapy, which corresponds to the age and psycho-physiological needs of preschool children. Despite the scientific and pedagogical community recognize the educational and developmental benefits of the game compared to traditional education, educators 
in preschool education institutions fully apply the latter to teach preschool children, feeling some uncertainty, because they lack the relevant theoretical knowledge and practical experience in the use of games for learning. The combination of game therapy with other art therapeutic methods of fairy-tale, isoand dramatherapy is pedagogically valuable. It is necessary to check the effectiveness of the developed methodology in the process of empirical research, which requires conducting a pedagogical experiment on the basis of Oyna Educational Centre. To implement its stating and control stages, it is necessary to adapt the Tromsø Scale to diagnose the levels of development of social intelligence in preschool children, taking into account their age characteristics, differences, and the like. However, we believe that this method does not take into account the diagnosis of the motivational and value component of social intelligence, which is manifested in the motives of communication and value orientations of a child (for himself, the others, the group), therefore, the criterion and diagnostic tools for determining the level of development of social intelligence of a preschool child requires refining.

It is important to share and introduce the acquired pedagogical experience of implementing the methods of developing the social intelligence of preschool children by means of art therapy in the educational process of preschool educational institutions. Research prospects can be, first, further development and testing of psychological and pedagogical technologies for the development of social intelligence of children, to contribute to their development, preservation of mental health. Second, in the comparative analysis of the results of an empirical study and determining the most sensitive age period for development social intelligence of an individual.

\section{References}

Astramovich, R. L., Lyons, C., \& Hamilton, N. J. (2015). Play therapy for children with intellectual disabilities. Journal of Child and Adolescent Counseling, 1(1), 27-36. https://doi.org/10.1080/23727810.2015.1015904

Bachar, P. (2008). Fair use of works of art in children's games. Education and the Law, 20(2), 151-163. https:/ / doi.org/10.1080/09539960902784186

Bailey, R. (2002). Playing social chess: Children's play and social intelligence. Early Years, 22(2), 163-173. https://doi.org/10.1080/09575140220151495

Buzan, T. (2002). The power of social intelligence. New York, US: Perfect Pound Publisher.

Cutter-Mackenzie, A., \& Edwards, S. (2013). Toward a model for early childhood environmental education: foregrounding, developing, and connecting knowledge through play-based learning. The Journal of Environmental Education, 44(3), 195-213. https:// doi.org/10.1080/00958964.2012.751892

Doğan, T., \& Çetin, B. (2009). The validity, reliability and factorial structure of the Turkish version of the Tromsø social intelligence scale. Educational Sciences: Theory $\mathcal{E}$ Practice, 9(2), 709-720.

Edwards, S. (2017). Play-based learning and intentional teaching: Forever different? Australasian Journal of Early Childhood, 42, 4-11. https://doi.org/10.23965/AJEC.42.2.01.

Enygin, D. V., Fominykh, N. Y., Bubenchikova, A. V., Arregi-Orue, J. I., \& Aubakirova, R. (2018). To the definition of the notion "multicultural educational environment". Astra Salvensis, 1(11), 601-616. 
Fominykh, N., Barsova, O., Zarudnaya, M., \& Kolomiytseva, N. (2016). Approaches to prospective economists professional foreign language training in computer orientated language learning environment. International Journal of Environmental and Science Education, 11(18), 12067-12083.

Katzmann, J., Goertz-Dorten, A., Hautmann, C., \& Doepfner, M. (2018). Social skills training and play group intervention for children with oppositional-defiant disorders/conduct disorder: Mediating mechanisms in a head-to-head comparison. Psychotherapy Research. https://doi.org/10.1080/10503307.2018.1425559

Kaukainen, A., Björkqvist, K., Lagerspetz, K., Österman, K., Salmivalli, C., Rothberg, S., \& Ahlbom, A. (1999). The relationship between social intelligence, empathy and three types of agression. Aggressive Behaviour, 25, 81-89.

Kisida, B., Bowen, D. H., \& Greene, J. P. (2018). Cultivating interest in art: Causal effects of arts exposure during early childhood. Early Childhood Research Quarterly, 45, 197-203. https://doi.org/10.1016/j.ecresq.2017.12.003

McLeod, Sh., Crowe, K., McCormack, L., White, P., Wren, Y., Baker, E., Masso, S., \& Roulstone, S. (2018). Preschool children's communication, motor and social development: Parents' and educators' concerns. International Journal of SpeechLanguage Pathology, 20(4), 468-482. https:// doi.org/10.1080/17549507.2017.1309065

Mora, L., van Sebille, K., \& Neill, L. (2018). An evaluation of play therapy for children and young people with intellectual disabilities. Research and Practice in Intellectual and Developmental Disabilities, 5(2), 178-191. https://doi.org/10.1080/23297018.2018.1442739

Müller, E., Naples, L. H., Cannon, L., Haffner, B., \& Mullins, A. (2018). Using integrated arts programming to facilitate social and emotional learning in young children with social cognition challenges. Early Child Development and Care, 189(14), 22192232. https://doi.org/10.1080/03004430.2018.1445732

Nasledov, A., \& Semenov, V. (2015). Modification of the Tromsø social intelligence scale for Russian students. Bulletin of Saint-Petersburg University, Series 12: Psychology. Sociology. Pedagogy, 4, 5-21.

Nind, M., \& Lewthwaite, S. (2018). Methods that teach: developing pedagogic research methods, developing pedagogy. International Journal of Research $\mathcal{E}$ Method in Education, 41(4), 398-410. https:/ / doi.org/10.1080/1743727X.2018.1427057

Nolan, A., \& Paatsch, L. (2018). (Re)affirming identities: implementing a play-based approach to learning in the early years of schooling. International Journal of Early Years Education, 26(1), 42-55. https://doi.org/10.1080/09669760.2017.1369397

Robinson, J. (1947). Developing social intelligence in children. Childhood Education, 23(9), $410-413$

Robson, S., \& Rowe, V. (2012). Observing young children's creative thinking: engagement, involvement and persistence. International Journal of Early Years Education, 20(4), 349-364. https:/ / doi.org/10.1080/09669760.2012.743098

Sidorchuk, T., \& Khomenko, N. (1998). Analysis of the plot meaning of fairy tales by means of the situation game "yes-no". Retrieved from http://www.trizminsk.org/e/23209.htm

Silvera, D. H., Martinussen, M., \& Dahl, T. I. (2001). The Tromsø social intelligence scale, a self-report measure of social intelligence. Scandinavian Journal of Psychology, 42(4), 313-319. https://doi.org/10.1111/1467-9450.00242

Taber, K. S. (2013). Chess variants \& games: for intellectual development and amusement. Teacher Development, 17(1), 148-149. https:/ / doi.org10.1080/13664530.2013.766492 
UNESCO. (2016). Education 2030: Incheon Declaration and Framework for Action for the implementation of Sustainable Development Goal 4: Ensure inclusive and equitable quality education and promote lifelong learning opportunities for all. Retrieved from https://unesdoc.unesco.org/ark:/48223/pf0000245656

UNESCO. (2018). Early childhood care and education. Retrieved from https://en.unesco.org/themes/early-childhood-care-and-education

Van Oers, B., \& Duijkers, D. (2013). Teaching in a play-based curriculum: Theory, practice and evidence of developmental education for young children. Journal of Curriculum Studies, 45(4), 511-534. https:/ / doi.org 10.1080/00220272.2011.637182

Wawra, D. (2009). Social intelligence. European Journal of English Studies, 13(2), 163-177. https:/ / doi.org 10.1080/13825570902907193

Wedeck, J. (1947). The relationship between personality and 'psychological ability'. British Journal of Psychology, 37, 133-151.

WHO. (2019). Child Development. Retrieved from https://www.who.int/topics/child_development/en/

Zarudnaya, M., Fominykh, N., Enygin, D., Kudysheva, A., Epifanov, D., \& Eferova, A. (2018). Methodological Approaches to University Instructors Professional Foreign Languages Competence Development. The Journal of Social Sciences Research, 5, 375-381. 


\section{Appendix 1}

\section{A Sample of a Diary}

Child's Name:

Age:

Date:

\begin{tabular}{|c|c|c|c|c|c|c|}
\hline \multirow{2}{*}{ Criteria } & \multirow{2}{*}{ Indicators } & \multicolumn{5}{|c|}{ Levels of Development } \\
\hline & & 4 & 3 & 2 & 1 & 0 \\
\hline 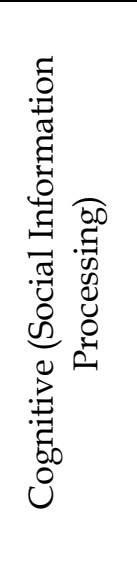 & $\begin{array}{l}\text { 1. Can predict other peoples' behaviour } \\
\text { 2. Knows how his/her actions will make } \\
\text { others feel } \\
\text { 3. Understands other peoples' feelings } \\
\text { 4. Understands others' wishes } \\
\text { 5. Can often understand what others are } \\
\text { trying to accomplish without the need for } \\
\text { them to say anything } \\
\text { 6. Can predict how others will react to } \\
\text { his/her behaviour } \\
\text { 7. Can often understand what others really } \\
\text { mean through their expression, body } \\
\text { language, etc. }\end{array}$ & & & & & \\
\hline 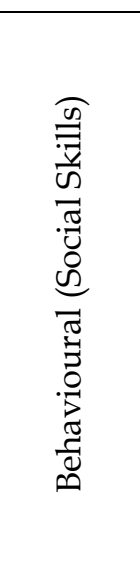 & $\begin{array}{l}\text { 1. Often feels uncertain around new people } \\
\text { who he/she doesn't know } \\
\text { 2. Fits in easily in social situations } \\
\text { 3. Is good at entering new situations and } \\
\text { meeting people for the first time } \\
\text { 4. Has a hard time getting along with other } \\
\text { people } \\
\text { 5. It takes a long time for him/her to get to } \\
\text { know others well } \\
\text { 6. Is good at getting on good terms with new } \\
\text { people } \\
\text { 7. Frequently has problems finding good } \\
\text { conversation topics }\end{array}$ & & & & & \\
\hline 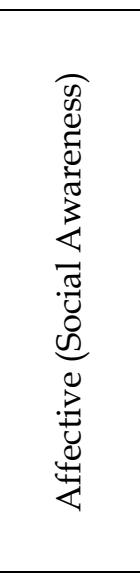 & $\begin{array}{l}\text { 1. It is difficult for him/her to understand } \\
\text { others' choices } \\
\text { 2. Is often surprised with things people do } \\
\text { 3. Feels that other people become angry with } \\
\text { him/her without explaining why } \\
\text { 4. Feels that people are often angry or } \\
\text { irritated with him/her when he/she says } \\
\text { what he/she thinks } \\
\text { 5. Finds people unpredictable } \\
\text { 6. Feels that he/she often hurts others } \\
\text { without realizing } \\
\text { 7. Is often surprized by others' reactions to } \\
\text { what he/she does }\end{array}$ & & & & & \\
\hline & \begin{tabular}{|l|l} 
Strengths & \\
\end{tabular} & & & & & \\
\hline & Opportunities & & & & & \\
\hline
\end{tabular}

\section{Suggestions for parents:}

